\title{
PEMBERDAYAAN MASYARAKAT MELALUI PENINGKATAN KAPITAL SPIRITUAL
}

\author{
Helena Anggraeni Tjondro Sugianto ${ }^{1 *}$, Priska Vasantan ${ }^{2}$ \\ ${ }_{1,2}$ Manajemen, Sekolah Tinggi Ilmu Manajemen Shanti Bhuana \\ Email: helena@shantibhuana.ac.id; priska@shantibhuana.ac.id \\ *Penulis korespondensi
}

\begin{abstract}
Abstrak: Program pengabdian masyarakat ini berangkat dari keprihatinan munculnya fenomena masyarakat sebuah dusun yang tidak terlalu peduli dengan kepentingan bersama. Tiap keluarga terkesan hanya memikirkan kepentingan diri sendiri saja sehingga kesejahteraan bersama sulit dicapai. Program ini dilakukan dengan menanamkan nilai-nilai spiritual yang dapat menyadarkan masyarakat untuk mau saling peduli dan bekerja sama sehingga kesejahteraan bersama dapat diraih dan dinikmati. Dalam hal ini pemberdayaan masyarakat terjadi melalui peningkatan kapital spiritual dengan menanamkan nilai-nilai luhur. Penanaman nilai-nilai ini dilakukan melalui pembinaan spiritual yang rutin diadakan selama satu semester bagi anak-anak, remaja, dan orang dewasa. Program ini dapat dikatakan berhasil dengan mulainya masyarakat bersedia bekerja sama untuk membuat tempat sampah bersama, membuat kebun sayur organik dan pupuk cair organik bersama yang dapat meningkatkan perekonomian rumah tangga, serta kerja bakti membersihkan lingkungan.
\end{abstract}

Kata kunci: Kapital spiritual; kesejahteraan masyarakat; peningkatan ketahanan ekonomi; sosial, dan ekologi.

\begin{abstract}
This program departs from the concern of the phenomenon of a village community that is not too care about the common interest. Each family seems to care about their own interests so that shared prosperity is difficult to be achieved. This program is carried out by instilling spiritual values that can awaken the public to care for one another and work together so that shared prosperity can be achieved and enjoyed. In this case, community empowerment occurs through increasing spiritual capital by instilling good values. The inculcation of these values is done through spiritual coaching which is routinely held for one semester for children, adolescents, and adults. This program can be asummed to be successful with the commencement of the community's willingness to work together to create a shared waste bin, create an organic vegetable garden and an organic liquid fertilizer that can improve the household economy, as well as working together to clean the environment.
\end{abstract}

Keywords: Spiritual capital; social welfare; increased economic; social and ecological resilience.

\section{PENDAHULUAN}

Masyarakat Kobeng memiliki banyak keuntungan strategis yang seharusnya dapat membuat mereka sejahtera secara ekonomi. Hal ini terjadi karena posisinya yang berada di kaki Bukit Jamur, sebuah ikon pariwisata yang terkenal di Kabupaten Bengkayang, Kalimantan Barat. Cukup banyak wisatawan lokal yang datang mendaki Bukit Jamur melalui Dusun Kobeng, namun sayangnya belum terlalu banyak mendatangkan keuntungan secara ekonomi bagi masyarakat. Selain itu Kabupaten Bengkayang berbatasan langsung dengan Malaysia sehingga secara posisi geografis Dusun Kobeng yang merupakan bagian dari Kabupaten Bengkayang diuntungkan jika ingin menjalankan bisnis lintas batas. Namun, sayangnya hal ini pun tidak memberikan keuntungan apa- apa secara ekonomi bagi masyarakat. Secara ekonomi masyarakat umumnya hidup dalam kemiskinan. Sebagian besar masyarakat adalah petani padi ladang dengan panen setahun sekali. Di samping itu juga menanam jagung pakan ternak dengan luas kebun terbatas, umumnya tidak sampai 1 ha. Semua pengerjaan kebun tersebut dilakukan secara manual sehingga produksi yang dihasilkan oleh setiap keluarga tidak terlalu banyak.

Secara keseluruhan, dusun terkesan kurang bersih dan tidak beraturan. Tidak ada tempat pembuangan sampah umum, dan Kepala Desa mengeluh sulit sekali mengumpulkan masyarakat kecuali jika ada janji pembagian beras. Tekanan ekonomi yang semakin sulit, banyaknya pendatang yang tidak terlalu dikenal, semua ini membuat masyarakat semakin memikirkan kepentingan diri sendiri dan tidak terlalu peduli dengan kepentingan ber- 
sama. Padahal, kalau ada kebersamaan akan ada banyak hal yang bisa dilakukan sehubungan dengan peningkatan kesejahteraan bersama. Sayangnya tiap keluarga terkesan tidak peduli dengan masalah bersama dan sibuk dengan urusannya masing-masing. Oleh sebab itu, dipandang perlu untuk menanamkan nilai-nilai untuk membangkitkan kesadaran pentingnya kebersamaan agar kesejahteraan bersama dapat ditingkatkan.

Hal yang memprihatinkan lainnya adalah jembatan yang menghubungkan dusun tersebut dengan dunia luar semakin lama semakin parah kondisinya dan tak seorang pun merasa terbeban untuk memperbaikinya. Jembatan tersebut terbuat dari kayu yang sudah berlubang di banyak tempat. Sebagian besar kayu juga sudah rapuh dan jika dilihat dari samping tampak banyak kayu yang sudah berguguran.

Semua fenomena ini menunjukkan lemahnya kapital spiritual yang ada di kalangan masyarakat setempat. Kurangnya kesadaran akan pentingnya kebersamaan perlu diatasi dengan penanaman nilai-nilai luhur mengenai persaudaraan dan kerja sama. Apabila nilai-nilai spiritual ini sudah tertanam dan membuahkan hasil, maka dapat dikatakan penghayatan spiritual masyarakat setempat ini sebagai sebuah kapital spiritual. Oleh karena itu, untuk dapat memberdayakan masyarakat di Dusun Kobeng dibutuhkan peningkatan kapital spiritual di kalangan mereka.

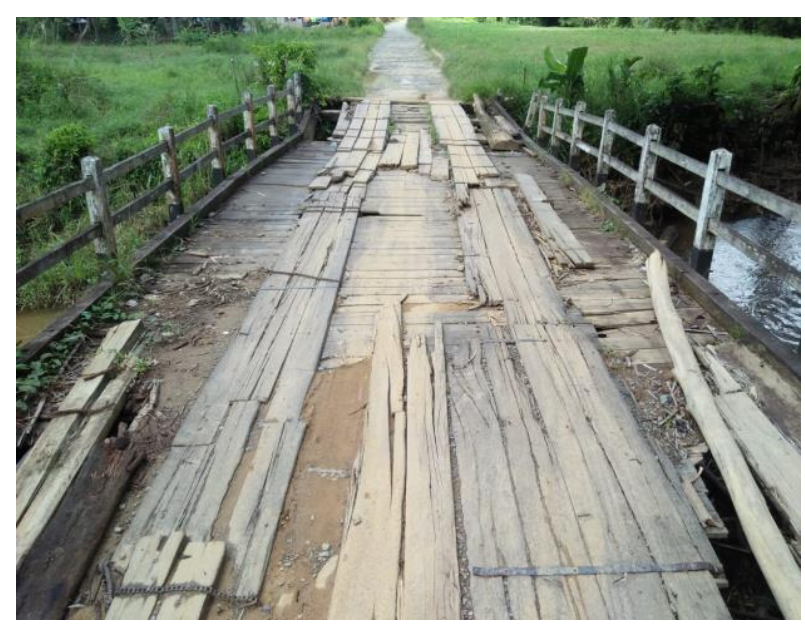

Gambar 1. Tampak atas Jembatan menuju Dusun Kobeng

Banyak komunitas masyarakat menikmati kesejahteraan di bidang ekonomi karena kapital spiritualnya yang bagus. Sudah bukan rahasia lagi bahwa penghayatan spiritual seseorang dapat membentuk motivasi bagi tindakan maupun cara berpikir seseorang. Secara spiritual, seseorang disebut miskin jika ia merasa sendirian, tidak memiliki komunitas maupun relasi yang dapat menopang kehidupannya (Grochmal, 2016). Oleh karena itu, seorang manusia sebagai makhluk sosial bagaimanapun membutuhkan relasi untuk dapat maju bersama. Terlebih di zaman revolusi industri 4.0 ini, semua industri berkembang karena adanya kolaborasi. Tidak ada lagi yang dapat mencapai keberhasilan secara individual.

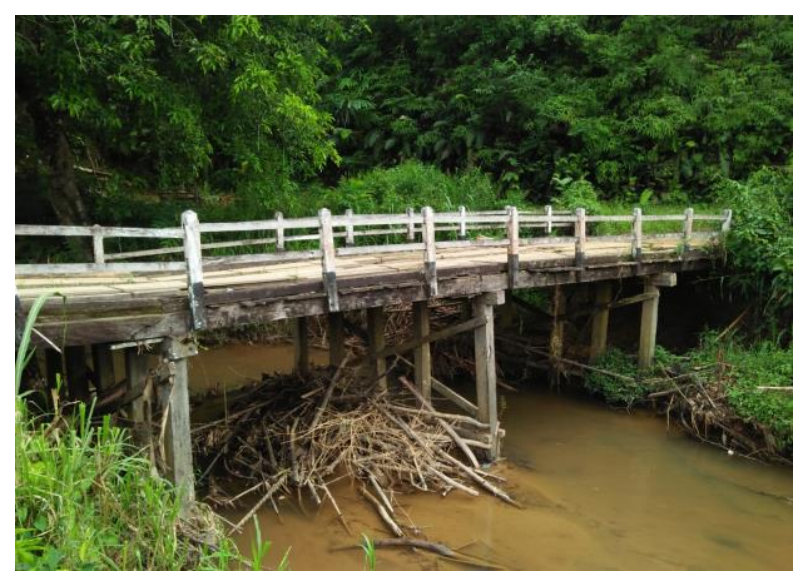

Gambar 2. Tampak samping jembatan

Untuk dapat maju bersama dalam sebuah kolaborasi dibutuhkan adanya kesepahaman nilainilai yang dihayati bersama. Penghayatan spiritual yang sama ini dapat menjadi sebuah motivasi dalam organisasi untuk mencapai tujuan bersama (Pandey, 2016). Dalam dunia manajemen dan bisnis, kapital spiritual telah menjadi sebuah modal yang tidak hanya dilirik namun terus dikembangkan. Beberapa penelitian menunjukkan bagaimana kapital spiritual memiliki peranan yang penting dalam dunia bisnis sebuah komunitas masyarakat (Artaya, 2013; Zhou and Hu, 2015; Hijriah, 2016).

Penanaman nilai-nilai luhur ke dalam sebuah komunitas masyarakat bisa melalui kearifan lokal yang dimiliki oleh penduduk pada umumnya, melalui tradisi dan budaya, bisa juga melalui agama (Grace, 2010; Habisch and Bachmann, 2016). Hal ini akan lebih memudahkan karena nilai-nilai yang ditanamkan sebetulnya tidak asing lagi bagi mereka karena sudah dikenal secara turun temurun melalui tradisi, atau sering mereka dengar melalui agama yang mereka hayati.

Kapital spiritual ini menjadi sebuah modal yang perlu untuk dikembangkan, terlebih dalam kondisi masyarakat yang tidak memiliki modal lainnya seperti modal finansial, modal personal (human capital), maupun modal sosial. Bagaimana pun setiap komunitas masyarakat tentunya memiliki nilai-nilai luhur yang diwariskan secara turun temurun dan menjadi tradisi atau kearifan lokal, atau pun nilai-nilai luhur yang diajarkan oleh agama. Itulah sebabnya kapital spiritual menjadi sebuah solusi untuk pemberdayaan masyarakat di Dusun Kobeng. Diharapkan dengan kapital spiritual yang ada, mereka mampu berkolaborasi untuk meningkatkan kesejahteraan bersama. 


\section{METODE PELAKSANAAN}

Penanaman nilai-nilai kepada masyarakat dimulai dengan cara memberikan pembinaan spiritual kepada anak-anak. Setiap hari Sabtu siang dan Minggu pagi anak-anak yang duduk di bangku SD dikumpulkan untuk belajar bersama. Pelajaran yang diberikan meliputi belajar berhitung, membaca, menulis, dan Bahasa Inggris dasar. Dalam belajar bersama itu kemudian diajarkan lagu-lagu yang membangkitkan semangat dan diselipkan penanaman nilai-nilai luhur seperti kejujuran, kedisiplinan, rajin menabung, dan lain-lain yang dipandang perlu.

Perlahan sebagaimana yang diharapkan, pembinaan kepada anak-anak ini menarik para remaja dan orang dewasa yang pada akhirnya mengajukan permohonan untuk juga dibina. Oleh karena itu secara rutin kemudian diberikan pembinaan spiritual kepada remaja dan dewasa (digabung) serta kepada anak-anak (tersendiri). Pembinaan spiritual ini dikemas dalam berbagai macam bentuk, misalnya rekoleksi, retret, Ibadat Sabda, dan lain-lain. Nilai-nilai luhur yang ditanamkan antara lain kejujuran, pentingnya kebersamaan dan persaudaraan, kepedulian serta sikap-sikap altruisme, dan sebagainya. Setiap acara yang diselenggarakan diikuti oleh cukup banyak masyarakat sehingga perlahan masyarakat mulai terbiasa dengan mengadakan kegiatan bersama. Acara-acara pembinaan yang awalnya sepi peminat semakin lama semakin ramai diikuti oleh masyarakat setempat.

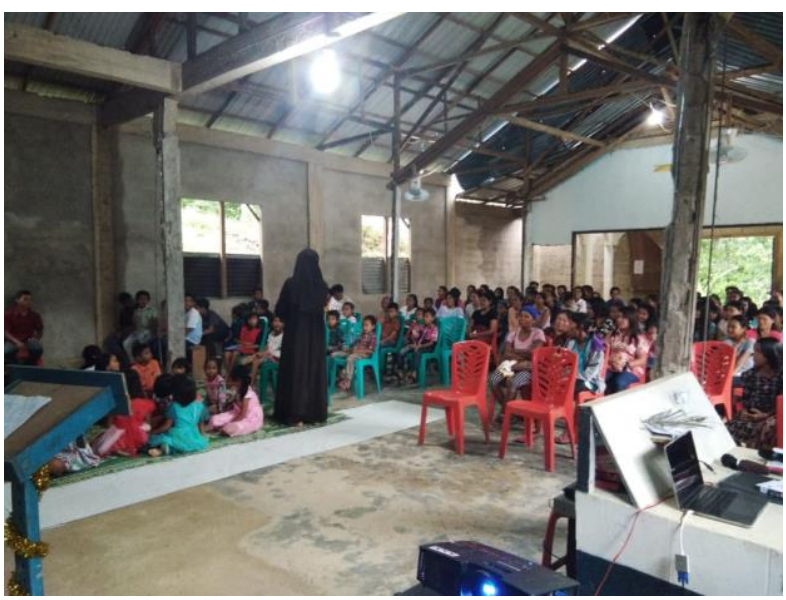

Gambar 3 Pembinaan Spiritual bagi umat di Dusun Kobeng.

Selain pembinaan spiritual, masyarakat diberikan juga berbagai edukasi seperti bahaya narkoba, rawannya pernikahan usia dini, serta perluasan wawasan untuk meningkatkan perekonomian rumah tangga melalui penanaman sayur organik dan pembuatan pupuk cair organik. Semua kegiatan bersama ini membuat masyarakat semakin akrab satu sama lain dan mulai terbiasa untuk mengadakan berbagai kegiatan bersama.

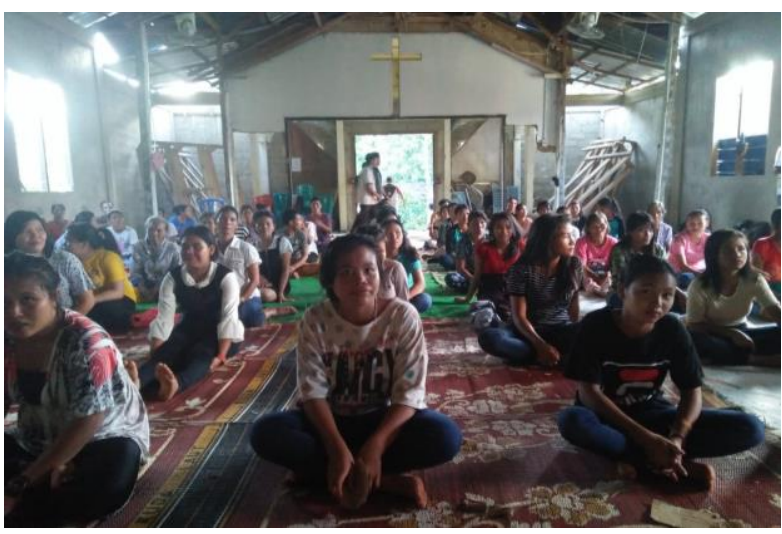

Gambar 4. Masyarakat Dusun Kobeng ketika mengikuti retret

\section{HASIL DAN PEMBAHASAN}

Setelah diselenggarakan pembinaan spiritual secara berkala, nilai-nilai luhur yang ditanamkan mulai menampakkan hasilnya. Rasa kepedulian terhadap lingkungan telah menggerakkan masyarakat untuk bergotong royong membuat tempat sampah bersama serta mengadakan kerja bakti untuk membersihkan dusun.

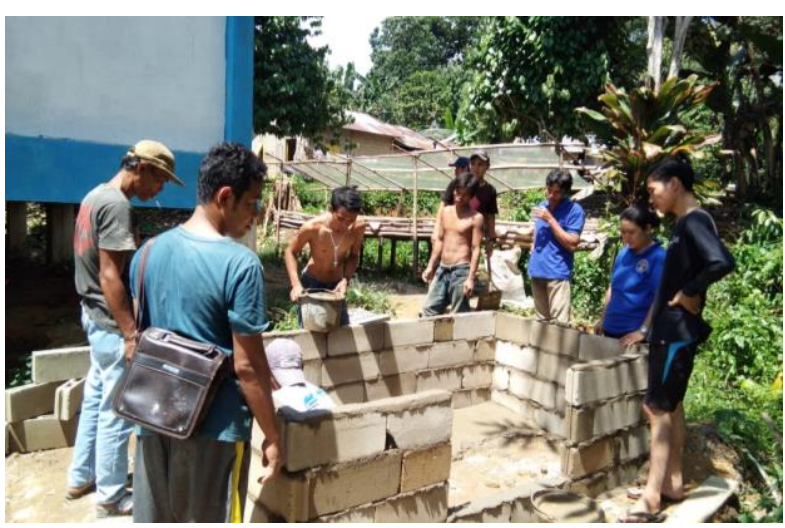

Gambar 5. Membuat tempat sampah bersama-sama

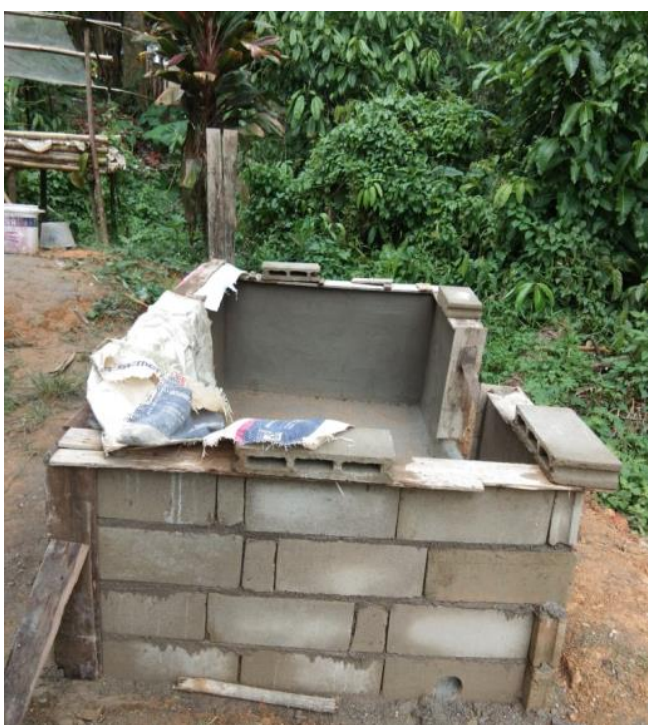

Gambar 6. Tempat Sampah yang dibuat bersama oleh masyarakat 


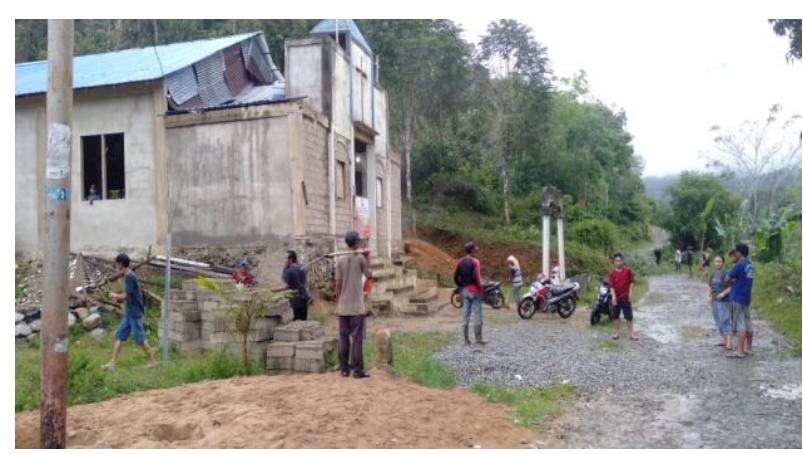

Gambar 7. Gotong royong membersihkan lingkungan

Selain itu masyarakat juga belajar bersama membuat kebun sayur organik. Hingga saat ini kebun sayur organik yang dibuat pertama kalinya di kebun Kantor Desa telah panen berkali-kali. Hasil dari kebun sayur organik ini oleh masyarakat sebagian dikonsumsi sendiri, sebagian lagi dijual ke pasar di Bengkayang. Dengan demikian, mereka mendapatkan pemasukan tambahan bagi ekonomi rumah tangga mereka.

Selain belajar membuat kebun sayur organik bersama, masyarakat juga bersama-sama diajarkan cara membuat pupuk organik dari sampah organik rumah tangga. Masyarakat diedukasi untuk memisahkan sampah organik dan anorganik, kemudian membuat komposter untuk mengubah sampah organik menjadi pupuk cair organik. Komposter ini dibuat dari bahan sederhana yang mudah didapat, yaitu dari ember bekas cat. Pupuk cair yang dihasilkan selain dapat dijual, dapat juga dipakai sendiri untuk kebun jagung masyarakat. Dengan demikian, tentunya hal ini akan membantu juga perekonomian rumah tangga masyarakat.

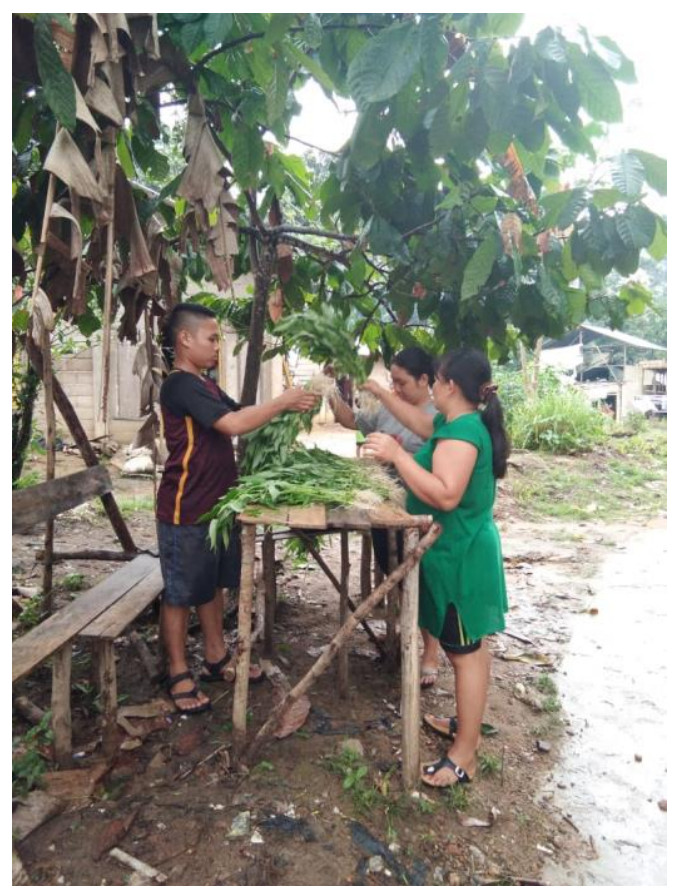

Gambar 8. Hasil sayur kebun organik

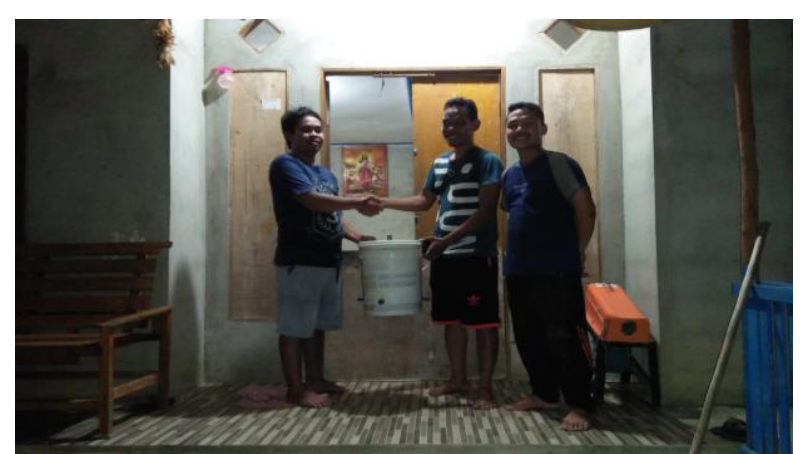

Gambar 9. Komposter untuk pembuatan pupuk cair organik

Satu hal lagi yang menggembirakan adalah ternyata di penghujung program pengabdian masyarakat ini, penduduk Dusun Kobeng bahu membahu memperbaiki jembatan mereka yang sudah rusak parah. Walau masih tetap berbahan baku kayu karena kurangnya dana namun jembatan sekarang sudah jauh lebih kokoh dan aman.

Banyak komunitas masyarakat miskin di dusun-dusun terpencil yang membutuhkan pertolongan untuk dapat bangkit dan menggerakkan pembangunan di daerahnya masing-masing. Sebagai sebuah daerah yang bergaris orbit jauh dari pemerintahan pusat, tentu tidak bisa menggantungkan harapan kepada uluran tangan pemerintah belaka. Kaum akademisi yang berada dekat dengan mereka tentunya diharapkan dapat memberikan kontribusinya untuk memberdayakan masyarakat yang miskin. Namun, keterbatasan finansial, fasilitas, dan sarana yang serba tidak memadai, seringkali membuat bingung bagaimana cara menolong mereka dan harus dimulai dari mana.

Melalui program pengabdian masyarakat ini ditemukan bahwa yang paling dapat menolong masyarakat yang miskin ini adalah mereka sendiri, yaitu dengan cara membangkitkan segala potensi yang mereka miliki. Meningkatnya kapital spiritual dalam sebuah komunitas masyarakat ternyata telah mampu memberikan motivasi kepada penduduk untuk berkolaborasi meningkatkan kesejahteraan bersama. Adanya kebersamaan ini telah membuat dusun yang tadinya tak berdaya dan saling acuh tak acuh ini mengalami peningkatan dalam dalam:

- Ketahanan ekonomi, melalui belajar bersama membuat kebun sayur organik dan pembuatan pupuk cair organik yang hasilnya dapat dikonsumsi sendiri sehingga menghemat pengeluaran rumah tangga, dan sebagian lagi dijual sehingga menambah pendapatan rumah tangga

- Ketahanan sosial, melalui adanya kebersamaan dalam berbagai kegiatan, rasa saling peduli, dan semangat altruisme yang mulai mewarnai masyarakat dusun

- Ketahanan ekologi, melalui gotong royong membersihkan lingkungan, penanaman sayur orga- 
nik, pembuatan bak sampah, dan kesadaran memisahkan sampah organik dan anorganik.

Peningkatan ketahanan ekonomi, sosial, dan ekologi ini menjadi sebuah isu yang urgen bukan saja karena masyarakat Dusun Kobeng yang miskin, namun karena posisinya yang berada di perbatasan. Dengan demikian, melalui peningkatan kapital sosial masyarakat bukan saja semakin berdaya namun juga terjadi peningkatan ketahanan nasional di perbatasan Indonesia, dalam hal ini ketahanan ekonomi, sosial, dan ekologi. Apabila digambarkan maka modelnya adalah seperti gambar 10.

\begin{tabular}{|c|c|c|}
\hline $\begin{array}{l}\text { Penamanam } \\
\text { Nilai-nilai } \\
\text { lewat } \\
\text { pembinaan } \\
\text { spiritual }\end{array}$ & $\begin{array}{l}\text { Peningkatan } \\
\text { Kapital } \\
\text { Spirtual dan } \\
\text { Pemberdayaan } \\
\text { Masyarakat }\end{array}$ & $\begin{array}{l}\text { Peningkatan } \\
\text { Ketahanan } \\
\text { Nasional di } \\
\text { kawasan } \\
\text { Perbatasan }\end{array}$ \\
\hline
\end{tabular}

Gambar 10. Model Program Pemberdayaan Masyarakat melalui Peningkatan Kapital Spiritual

\section{REKOMENDASI}

Pembinaan selama satu semester bukan waktu yang pendek tapi juga tidak terlalu panjang. Setidaknya, untuk pembinaan spiritual sebetulnya waktu 6 bulan tidak cukup. Setelah dilakukan secara intensif selama 6 bulan, perlu sesekali dilakukan pembinaan lanjutan agar apa yang sudah ditanamkan tidak lenyap seiring waktu. Kebiasaan untuk berkumpul bersama dan bekerja untuk kepentingan bersama perlu terus dilakukan hingga menjadi kebiasaan yang mendarah daging bagi masyarakat kampung.

Para pengabdi masyarakat selanjutnya yang akan terjun untuk memberikan pembinaan lanjutan tentunya perlu mengetahui dulu pembinaan apa saja yang sudah diberikan. Dengan demikian pembinaan dapat berkelanjutan dan sesuai dengan konteks kondisi masyarakat yang ada di kampung tersebut.

\section{KESIMPULAN}

Nilai-nilai spiritual yang dihayati oleh masyarakat dapat menjadi sebuah kapital spiritual ketika mendatangkan keuntungan bagi masyarakat.
Melalui berbagai pembinaan, masyarakat yang awalnya tidak berdaya secara ekonomi dapat menjadi lebih berdaya setelah menghayati nilai-nilai kebersamaan, persaudaraan, dan kejujuran. Semangat altruisme yang tertanam ternyata berdampak positif terhadap kesejahteraan bersama.

Selain ekonomi, ternyata masyarakat juga lebih berdaya di bidang sosial dan ekologi. Dengan demikian dapat disimpulkan, bahwa pemberdayaan kapital spiritual bagi masyarakat dapat meningkatkan ketahanan ekonomi, sosial, dan ekologi bagi masyarakat Kampung Kobeng yang terletak di kabupaten perbatasan, Bengkayang, Kalimantan Barat.

\section{DAFTAR PUSTAKA}

Artaya, I. P. (2013) 'Spiritual Capital In Salesmanship', in Spiritual Capital in Salesmanship. February 2. Surabaya: Narotama University Press. Available at: https://www.researchgate. net/publication/331357999.

Grace, G. (2010) 'Renewing spiritual capital: an urgent priority for the future of Catholic education internationally', International Studies in Catholic Education, 2(2), pp. 117-128. doi: 10.1080/19422539.2010.504017.

Grochmal, S. (2016) 'Spirituality of unity in management - Economy of Communion', Cogent Business \& Management. Cogent, 3(1), pp. 118. doi: 10.1080/23311975.2016.1140618.

Habisch, A. and Bachmann, C. (2016) 'Empowering practical wisdom from religious traditions: a ricoeurian approach', International Journal of Corporate Social Responsibility. International Journal of Corporate Social Responsibility, 1(1), p. 10. doi: 10.1186/s40991-016-0011-7.

Hijriah, H. Y. (2016) 'Spiritualitas Islam dalam Kewirausahaan', Tsaqafah, 12(4), pp. 187-208.

Pandey, S. (2016) 'Impact of spiritual capital on work motivation among employees: an exploratory study Impact of spiritual capital on work motivation among employees', 2(3), pp. 42-52.

Zhou, Y. and Hu, A. (2015) 'Capital with beliefs-a study of charitable donations of private business owners in Wenzhou, China', The Journal of Chinese Sociology. The Journal of Chinese Sociology, 2(1), p. 8. doi: 10.1186/ s40711-015-0010-1. 